\title{
O CEARÁ NA ANPEGE
}

\author{
Luiz Cruz Lima \\ Professor da Universidade Estadual do Ceará \\ 1.cruzlima@uol.com.br
}

\begin{abstract}
Resumo
Este trabalho ressalta a participação dos Programas de Pós-graduação do Estado do Ceará na ANPEGE, desde 1997. Acrescenta, ainda, o perfil de 50 (cinquesnta) geógrafos do Ceará, em 2005, como demonstração da vida acadêmica da geografia capaz de admitir a institucionalização de um doutorado em Fortaleza.
\end{abstract}

Palavras-chave: geografia - pós-graduação - produção acadêmica.

\begin{abstract}
This work emphasizes the participation of the Postgraduation Programs of the State of Ceará in ANPEGE since 1997. It also adds the outline of 50 geographers from Ceará in 2005 as a demonstration of their performance in geography which enables it to admit officialization of a doctorate in Fortaleza.
\end{abstract}

Key Words: geography - postgraduation - academic production

\section{$0 \bigcirc 0$}

O Ceará, através do Curso de Mestrado da Universidade Estadual do Ceará, ingressou na Associação Nacional de Pós-graduação e Pesquisa em Geografia - ANPEGE, no momento do $2^{\circ}$ Encontro Nacional, ocorrido na Universidade Federal do Rio de Janeiro, de 7 a 10 de setembro de 1997, integrando-se aos 14 Programas de pós-graduação então existentes, com apenas 4 doutorados.

Apesar de governado por um presidente intelectual, curtas verbas para apoio à pesquisa e restrições de bolsas, com fortes taxas de inflação, marcaram o cenário acadêmico do Brasil na segunda metade dos anos 90, quando houve, no entanto, um acelerado movimento de institucionalização de cursos de pósgraduação stricto sensu, em todas as áreas, acompanhado pela Geografia, passando de 11 em 1996 para 21, em 2001. Mesmo assim, com esforço e dedicação da comunidade científica do país, "a titulação de doutores salta de 2.497, em 1995, para 5.335, em 2000, mas a oferta de bolsa fica praticamente estagnada", como nos informa o Prof. Manuel Domingos em brilhante resenha da história do CNPq (Jornal O POVO de 17/07/05). Nesses primeiros anos do século, os cursos de formação de mestres e doutores em Geografia já chegam a 29, distribuídos, pela primeira vez, por todas as regiões do país: 11 no Sudeste, 7 no Nordeste, 6 no Sul, 4 no Centro-Oeste e 1 na região Norte, ampliando a representatividade da ANPEGE no país.

A ANPEGE fora criada em 1993, por ocasião do V Encontro Nacional de Pós-graduação e Pesquisa em Geografia (ENPGPG), em Forianópolis, como assinala GERARDI em artigo na primeira revista da entidade, em 2003. A autora lembra que esse fato decorreu de idéias já alimentadas nesses Encontros. No Relatório dos Grupos de Trabalho do $2^{\circ}$ ENPGPG, sugere-se "a criação de um mecanismo eficiente de intercâmbio e divulgação entre os Programas de pós-graduação” (p. 247 dos Anais). Isso é realimentado pelo Prof. Dr. José Alexandre Filizola Diniz, do Programa da Universidade Federal de Sergipe, no Encontro seguinte, de 1987. Como se nota, a proposta foi maturada por seis anos. O fato relevante é que a geografia brasileira tem trabalhado intensamente para manter dinâmica uma agremiação por mais de setenta anos, a Associação dos Geógrafos Brasileiros (AGB) que congrega os estudiosos da geografia e 
todos os interessados em discutir o espaço. Além da AGB, na dúzia de anos últimos, a comunidade de pesquisadores e de docentes de mais alto nível do campo do conhecimento geográfico sustenta um organismo que ajuda o desempenho científico das instituições de pesquisa e de Programas de pós-graduação no país.

Nesse sentido, os que fazem a geografia no Ceará vêm colaborando no engrandecimento dessa ciência, simbolizado na história da formação do pensamento acadêmico local, desde 1947; na participação de uma AGB mais próxima das lutas a favor da desmistificação do espaço dominado por uma minoria, lutas marcadas a partir do histórico $3^{\circ}$ Encontro Nacional de Geógrafos em 1978, em Fortaleza; advento de um Programa de Pós-graduação stricto sensu em março de 1996, na UECE, apadrinhado por Milton Santos; a pós-graduação fortalece-se, mais ainda, com a implantação do Curso de Mestrado Acadêmico em Geografia, em 2004, na Universidade Federal do Ceará (UFC). Finalmente, no V Encontro da ANPEGE, em Florianópolis, o Ceará tomou a decisão de encabeçar a responsabilidade, com a participação do Programa da UFRN, de conduzir a entidade no biênio 2003-2005, a partir de uma proposta audaciosa e agora concluída. Muitos outros fatos revelariam o trajeto do desempenho dos geógrafos do Ceará, caso aqui objetivássemos relatar a trajetória desses profissionais.

Não se desconhece a contribuição de centros acadêmicos mais avançados na formação da massa crítica universitária cearense, para o fortalecimento e estímulo ao desempenho da pesquisa, ensino e integração aos movimentos sociais. Nesses aspectos, os colegas de Porto Alegre, Recife, Salvador, Rio de Janeiro e São Paulo nos ofereceram suas experiências na formação acadêmica e no envolvimento das discussões para a construção de uma geografia sintonizada com a vida, com a sociedade.

Foi marcante a realização em Fortaleza, em 1978, do $3^{\circ}$ Encontro Nacional de Geógrafos, a partir do qual sucederam-se cursos, conferências, participação em pesquisa e eventos com grandes nomes da ciência geográfica nacional e internacional, patrocinados pelas duas Universidades públicas presentes em Fortaleza. É reconhecível o papel que tiveram, para nosso melhor desempenho, os destacados geógrafos Michel Rochefort, Milton Santos, Maria Adélia de Souza, Sylvio Bandeira de Mello, Maria do Carmo Galvão, Jan Buton, Ariovaldo Umbelino, Manuel Correia, José Bueno Conti, Paul Claval, Bertha Becker, Iná de Castro, Ana Fani Carlos, Adyr Balestreri, Antonio Carlos Morais, entre tantos outros, que participaram intensivamente em aulas, conferências, avaliações e debates em nossas Universidades. Esses fatos estimularam o aperfeiçoamento e a qualificação dos profissionais da geografia cearense, com múltiplas produções científicas e técnicas. Assim é que, além das Academias, em setores públicos e outras organizações sociais estão presentes professores, pesquisadores, consultores e técnicos geógrafos de real valor.

Muitas são as experiências acumuladas em diferentes campos de trabalho desempenhadas pelos profissionais da geografia no Ceará: participação nos movimentos sociais; orientação das lutas pela defesa do meio ambiente; consultorias gratuitas às comunidades agredidas pelas cobiças desenfreadas dos especuladores imobiliários; colaboração a parlamentares comprometidos com a luta do povo humilde; consultorias aos órgãos públicos, elaboração de projetos e de desenvolvimento de pesquisa, publicação de muitos livros científicos, edição de uma importante revista especializada, realização de múltiplos eventos científicos de amplitude nacional e internacional para debater questões teóricas e práticas dos problemas espaciais. Além dessa agenda, destaca-se, nos últimos dez anos, a criação de dois cursos de mestrado acadêmicos em geografia, tendo já pós-graduado mais de setenta profissionais, alguns já doutorados por outras universidades do país.

\section{Uma amostra do perfil dos geógrafos no Ceará}

Em fins de 2004 e início de 2005, procuramos conhecer o perfil da maior parte dos professores e téc- 
nicos que se dedicam à geografia no Ceará. Para tanto, entrevistamos cerca de 30 mestres e 20 doutores, com base no seguinte roteiro:

1. Formação acadêmica: níveis, instituição e ano de conclusão.

2. Função no mercado de trabalho.

3. Produção nos últimos três anos: livro, artigo em periódicos, projetos, relatórios e mapas.

4. Conceito da ciência geográfica.

5. Objeto de estudo da geografia.

6. Conquistas e avanços da Geografia na atualidade.

7. Contribuição da Geografia para conhecer a realidade vivida pelo povo cearense.

8. Como o geógrafo contribui para mudar a realidade do país e do Estado do Ceará.

9. Participação da geografia para a formação do cidadão.

10. Cinco destacados geógrafos da atualidade.

A partir de 50 (cinqüenta) questionários respondidos por 30 (trinta mestres e 20 (vinte) doutores, observamos que apenas 7 (sete) ou 14,0 e 17 (dezessete) ou 34,0\% concluíram, respectivamente, a graduação e o mestrado em outros Estados. Dos doutores, 75\% se graduaram nas três Universidades em Fortaleza (UFC,UECE e UNIFOR). Seis obtiveram sua titulação na França e Espanha, sendo a USP a preferida por cerca de 9 (nove) ou $45 \%$ dos 20 (vinte) doutores.

Considerando o ano de titulação, somente 3 (três) se doutoraram na década de 1980, enquanto os demais defenderam suas teses nos anos 90 ou em anos recentes (14 deles entre 1996 e 2005). Interessante que 13 dos doutores têm mais de 20 (vinte) anos de graduados. Isto evidencia uma formação sem os parâmetros técnicos exigidos pela atual modernidade (programas de computadores, internet etc.), o que resulta alguns professores-doutores não dominarem o uso de geotecnologias ou mesmo de computadores, embora compensados atualmente por seus orientandos e funcionários exímios nesses recursos tecnológicos.

Os cursos de mestrado em Desenvolvimento e Meio Ambiente, com forte participação do Departamento de Geografia da UFC, e o Mestrado Acadêmico em Geografia da UECE contribuíram para que somente 1 (um) de nossos mestres se formasse em outro Estado. Dos 30, 28 (vinte e oito) concluíram entre 1996 e 2005. A presença atual de dois mestrados em Fortaleza vem contribuindo para graduados na década de 1980 retomarem sua qualificação, o que ocorrera com 7 (sete) dos entrevistados. É notório como a USP detinha a preferência na formação dos que desejavam prosseguir na pós-graduação: metade dos doutores entrevistados realizaram seu mestrado e 9 (nove) se doutoraram nessa importante Universidade brasileira.

Todos os doutores entrevistados têm a docência como ocupação principal, embora 3 (três) se revelem consultores ou assessores de órgãos de governo. Dos mestres, 19 (dezenove) são professores, 6 (seis) técnicos de órgãos públicos e 3 (três) mantêm-se, ainda, fora do mercado de trabalho formal.

É significativa a disposição do corpo pensante da geografia cearense em se voltar à produção científica e técnica. Todos os ítens relacionados no questionário foram completados, destacando-se a produção de livros, artigos de periódicos, projetos e relatórios técnicos.

Voltando-se à compreensão teórico-metodológica da geografia, encontramos vários profissionais arredios à abordagem dialética dos fenômenos espaciais, circunscrevendo-se no tratamento positivista. Isto é evidente quando 16 (dezesseis), ao tratar dos quesitos do questionário sobre conceituação e objeto de estudo da geografia, asseguram que essa ciência estuda as relações sociedade x natureza em diferentes escalas ou ser a geografia uma ciência de síntese. Ao lado desses, no entanto, 22 (vinte e dois) consideraram a espacialidade social, o movimento da sociedade, o espaço produzido pelo trabalho social 
ou a produção e organização do espaço como o objeto da ciência geográfica. Apenas meia dúzia dos entrevistados se omitiram, enquanto alguns apresentaram respostas evasivas.

É sabido que, nas duas últimas décadas, a geografia retomou reconhecimento de ciência capaz de discernir temas da atualidade e apresentar propostas para as crises da sociedade. Esse fato é destacado por quase todos os entrevistados, quando revelam que há mais respeito ao profissional com atuação permanente e destacada na vida política e na sociedade, tratando de questões teóricas ou técnicas. Além disso, o geógrafo sobressai-se nos debates teóricos, dado o aperfeiçoamento das categorias analíticas presentes na literatura geográfica das últimas décadas. Pode-se afirmar que isto tem elevado a auto-estima dos que pensam o espaço geográfico. Além desta compreensão, alguns indicam como grande avanço da geografia a inserção das geotecnologias - cartografia digital, geoprocessamento, GPS etc. - , assim como a expansão dos cursos de pós-graduação, onde se substanciam os grandes debates teóricos, os estímulos à criatividade e à produção intelectual, de onde brotam propostas para os problemas sócio-espaciais.

Nessa linha de observações, há uma série de evidências de contribuição da geografia em conhecer a realidade do povo e dela participar com renovada postura crítica, sem esquivar-se de oferecer propostas de ação e aplicabilidade. Com esse avanços e conquistas, no tratamento concreto da realidade, os geógrafos cearenses apontam variadas formas metodológicas, com base em novas posturas epistemológicas da ciência geográfica:

1. "A geografia, além de trazer uma leitura analítica e sintética abrangente da realidade, a partir do prisma espacial, vem contribuindo bastante ao oferecer um olhar crítico sobre as relações estabelecidas pela sociedade de consumo do seu espaço. Ela revela a repartição perversa e desigual dos bens e serviços da sociedade, indicando o uso indiscriminado dos recursos naturais e explicitando, como nenhuma ciência humana, os novos ritmos de difusão espacial pelos objetos, pelas técnicas e pela informação".

2. "A geografia ultrapassou os muros das salas de aula, permitindo a compreensão das mudanças que ocorrem no mundo pela associação entre teoria e prática".

3. "Aprofundamento das análises da dinâmica social e natural realizado pela geografia, o que tem contribuído para a compreensão dos problemas sociais, econômicos, políticos e ambientais que se materializam no espaço e que podem fundamentar as políticas públicas, visando a transformação de uma sociedade mais justa e com menos desequilíbrios".

4. "A geografia tem oferecido informações para decisões públicas e privadas para mudança de vida da sociedade contemporânea".

5. "A geografia oferece conscientização da realidade sócioespacial, contribuindo para a sociedade se mobilizar".

6. "A geografia tornou-se necessária para explicar o movimento da sociedade".

7. "A geografia desenvolveu-se no sentido de conquistas sócio-ambientais e lutas sociais, muito contribuindo na área de ensino e no planejamento territorial".

8. "Com a politização iniciada no final da década de 1990 e várias preocupações epistemológicas, a geografia contribuiu, de certo modo, para uma melhor compreensão da realidade vivenciada pelo povo".

Na essência dessas situações teóricas e práticas, há objetivos explícitos com o intuito de mudar a realidade sócioespacial que venha contribuir para melhorar as condições de vida das coletividades. Abaixo, relacionamos os 13 (treze) principais objetivos indicados: 
1. Formar cidadãos comprometidos com a sociedade;

2. Apresentar soluções para os problemas ambientais;

3. Colocar-se a serviço do poder público;

4. Engajar-se em pesquisa sobre os problemas sociais para solucioná-los;

5. Subsidiar o planejamento público e privado;

6. Divulgar os conhecimentos obtidos em pesquisa;

7. Desmascarar e desfazer os discursos já formados;

8. Revelar todas as possibilidades de ação e transformação da sociedade;

9. Identificar conflitos entre os grupos sociais e entre sociedade e natureza para apresentar propostas de solução;

10. Visar a prática da concepção do desenvolvimento sustentável;

11. Participar da elaboração do conhecimento geográfico e dos processos organizativos da sociedade;

12. Executar trabalhos científicos para mudar a sociedade na forma de pensar e

13. Fornecer seu conhecimento para a classe trabalhadora.

A par desses objetivos e das novas posturas de pensar e de agir, a comunidade geográfica do Ceará aponta uma agenda de propostas e de realizações concretas, dentro da concepção de que contribuam para a melhoria da vida social:

1. Estudo da região costeira e sistemas ambientais;

2. Conscientização da população para a reforma agrária;

3. Informações às pessoas para o processo de desalienação;

4. Pesquisa com as ONGs.;

5. Discussão dos problemas de uso e ocupação do solo;

6. Abordagem das questões sócioespaciais nas dissertações de mestrado;

7. Projeto de caráter comunitário;

8. Envolvimento em diferentes discussões dos problemas sociais;

9. Elaboração de diagnósticos sócio-ambientais;

10. Desenvolvimento de projetos específicos para melhorar a vida das pessoas;

11. Estudo de zoneamento ecológico e econômico;

12. Revelar para que e para quem é utilizado o território.

Julgamos importante ter uma melhor visibilidade do conhecimento da literatura pelos entrevistados. Solicitados a indicar cinco destacados autores, ordenamos os mais lembrados, com 38 (trinta e oito) até 5 (cinco) citações: 1. Milton Santos, 2. Manuel Correia de Andrade, 3. David Harvey, 4. Aziz Ab'Sáber, 5. Denise Elias de Souza, 6. Antonio Carlos Morais, 7. Luiz Cruz Lima, 8. Paul Claval, 9. Rogério Haesbaert, 10. Marcos José Nogueira de Souza, 11. José Borzachiello da Silva, 12. Roberto Lobato, 13. Ana Fani Carlos, 14. Ariovaldo Umbelino.

Foi citado um total de sessenta e cinco (65) autores, em sua maioria geógrafos brasileiros da atualidade. Isso revela que a literatura geográfica está bem presente nas bibliotecas dos geógrafos cearenses.

Por fim, lembramos que no Ceará funcionam cinco cursos de graduação em geografia, três (3) no interior do Estado e dois (2) na Capital, todos em universidades públicas. Dois mestrados em geografia na Capital absorvem parte da demanda dos que desejam dar continuidade aos seus estudos acadêmicos. Anualmente, são oferecidas em torno de vinte e cinco (25) vagas, com uma média de dois (2) candidatos 
por vaga. Pelo número de mestres presentes no Estado, pela presença de cursos universitários e pela demanda já revelada, a comunidade acadêmica exige o funcionamento de um doutorado em geografia em Fortaleza, o que fortaleceria, ainda mais, a representatividade da ANPEGE que caminha para uma nova década de importantes contribuições para a ciência geográfica brasileira.

\section{Referências}

GALVÃO, Ma. do Carmo e MIRANDA, Mariana Helena S, P. de (Org.). ANAIS. $2^{\circ}$ Encontro Nacional de Pósgraduação em Geografia. 14-16/set/1986. Universidade Federal do Rio de Janeiro.

GERARDI, Lúcia Helena de Oliveira. ANPEGE - o resgate de uma história. REVISTA DA ANPEGE, ano 1, n. 1. Curitiba-PR: 2003. P. 9-16.

JORNAL O POVO. Fortaleza, Ceará, 17/07/05.

Recebido em julho de 2005 Aceito em agosto de 2005 